\title{
BMJ Open Are adverse events in newly trained home dialysis patients related to learning styles? A single-centre retrospective study from Toronto, Canada
}

\author{
Bourne Lewis Auguste (D) ,1,2 Michael Girsberger, ${ }^{3}$ Claire Kennedy, ${ }^{3}$ \\ Thatsaphan Srithongkul, ${ }^{3}$ Margaret McGrath-Chong, ${ }^{3}$ Joanne Bargman, ${ }^{2,3}$ \\ Christopher T Chan ${ }^{3}$
}

To cite: Auguste BL, Girsberger M, Kennedy C, et al. Are adverse events in newly trained home dialysis patients related to learning styles? A single-centre retrospective study from Toronto, Canada. BMJ Open 2020;10:e033315. doi:10.1136/ bmjopen-2019-033315

- Prepublication history for this paper is available online. To view these files, please visit the journal online (http://dx.doi. org/10.1136/bmjopen-2019033315).

Received 30 July 2019 Revised 29 0ctober 2019 Accepted 23 December 2019

Check for updates

(C) Author(s) (or their employer(s)) 2020. Re-use permitted under CC BY-NC. No commercial re-use. See rights and permissions. Published by BMJ.

${ }^{1}$ Medicine; Division of Nephrology, Sunnybrook Health Sciences Centre, Toronto, Ontario, Canada

${ }^{2}$ Medicine; Division of Nephrology, University of Toronto, Toronto, Ontario, Canada

${ }^{3}$ Medicine; Division of Nephrology, University Health Network, Toronto, Ontario, Canada

Correspondence to Dr Bourne Lewis Auguste; bourne.auguste@sunnybrook.ca

\section{ABSTRACT}

Objectives Home haemodialysis (HD) and peritoneal dialysis (PD) have seen growth in utilisation around the globe over the last few years. However, home dialysis, with its attendant technical complexity and risk of adverse events continues to pose challenges for wider adoption. We examined whether differences in patients' learning styles are associated with differing risk of adverse events in both home HD and PD patients.

Design Retrospective cohort study.

Setting Tertiary care hospital in Toronto, Ontario, Canada. Participants One hundred and eighteen prevalent adult ( $\geq 18$ years) home dialysis patients (40 PD and 78 home $\mathrm{HD}$ ) were enrolled. Patients on home dialysis for less than 6 months or receiving home nursing assistance for dialysis were excluded from the study.

Interventions Enrolled patients completed (VARK) Visual, Aural, Reading-writing and Kinesthetic questionnaires to determine learning styles.

Primary and secondary outcome measures Home HD and PD adverse events were identified within 6 months of completing home dialysis training. Event rates were then stratified and compared according to learning styles. Results Thirty patients had a total of 53 adverse events. We used logistic regression analysis to determine unadjusted and adjusted ORs for a single adverse event. Non-visual learners were 4.35 times more likely to have an adverse event $(p=0.001)$. After adjusting for age, gender, dialysis modality, training duration, dialysis vintage, prior renal replacement therapy, visual impairment, education and literacy, an adverse event was still four times more likely among non-visual learners compared to visual learners $(p=0.008)$. A subgroup analysis of home HD patients showed adverse events were more likely among non-visual learners (OR 11.1; $p=0.003$ ), whereas PD patients showed a trend for more adverse events in nonvisual learners (OR: $1.60 ; p=0.694)$.

Conclusions Different learning styles in home dialysis patients exist. Visual learning styles are associated with fewer adverse events in home dialysis patients within the first 6 months of completing training. Individualisation of home dialysis training by learning style is warranted.
Strengths and limitations of this study

- First study examining learning styles in both home haemodialysis and peritoneal dialysis patients.

- Visual learning may have a lower adverse event risk in the first 6 months of training completion.

- Highlights that differences in learning styles exist between home dialysis patients.

- Visual, Aural, Reading-writing and Kinesthetic has not yet been validated in home dialysis patients.

- Small single-centre observational study.

\section{INTRODUCTION}

Global trends have seen an increased uptake in both home haemodialysis (HD) and peritoneal dialysis (PD) over the last several decades. This increase in utilisation has been partly driven by priorities that focus on better clinical outcomes while reducing healthcarerelated cost and improving patient quality of life. ${ }^{1-5}$ Home HD improves blood pressure control, reduces left ventricular hypertrophy and enhances middle molecular clearance by augmenting the frequency and duration of $\mathrm{HD}^{6-8}$ Similarly, PD offers additional benefits to patients including slower decline in residual renal function, effective small solute clearance and avoidance of bleeding and other vascular access related complications. ${ }^{9-11}$ However, the technical complexity of home dialysis and associated adverse event risk pose significant threats to the continued growth and sustainability of home dialysis.

Adverse events can be due to a variety of reasons including patient, technological or system related factors. However, recent observational data has shown that the majority of adverse events among home dialysis patients are due to patient-related errors. ${ }^{12} 13$ Patients 


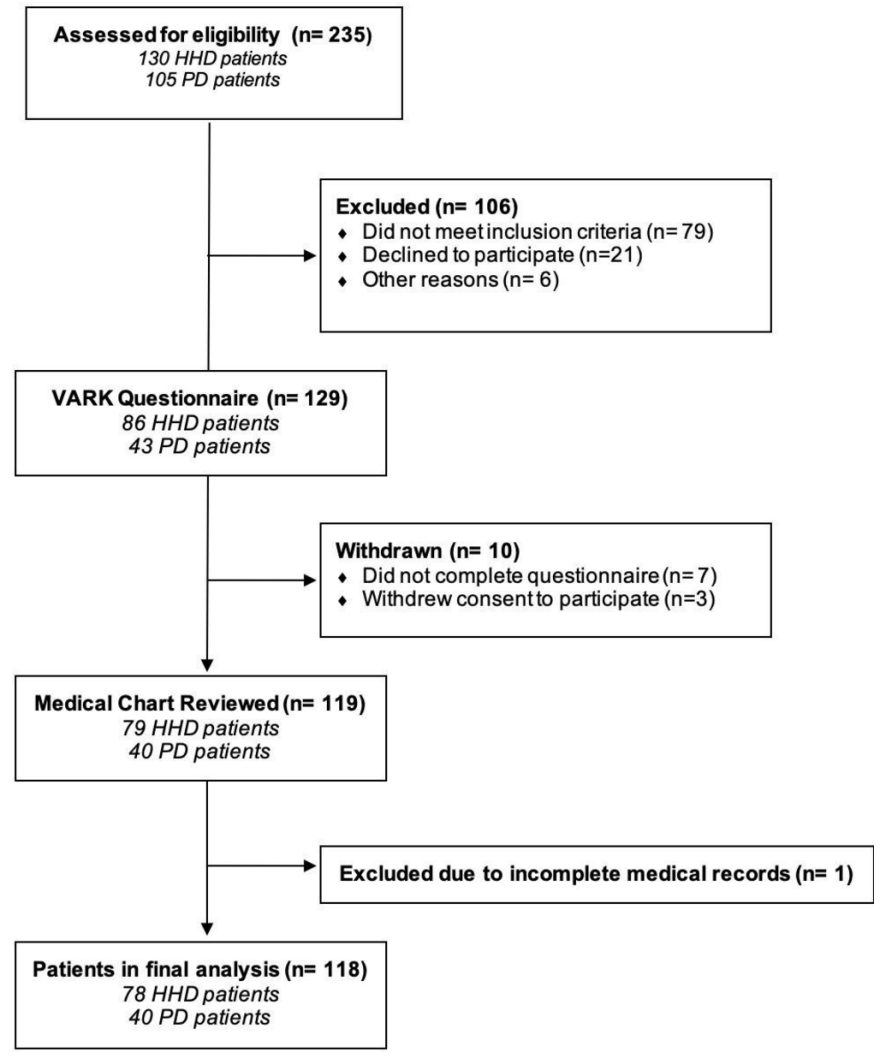

Figure 1 Consort diagram showing patient selection for the study. HHD, home haemodialysis; PD, peritoneal dialysis; VARK, Visual, Aural, Reading-writing and Kinesthetic.

also have diverse backgrounds with varying levels of education and preferred learning styles. Additionally, recent published data have demonstrated patients with advanced kidney disease may have challenges in understanding learning material and practitioners should tailor education according to the needs of the patients. ${ }^{14}$ Learning style refers to the preference and effectiveness of the mode of instruction for each individual. ${ }^{15-17}$ Therefore, accommodating to individual learning styles may impact on long-term retention of knowledge, which may in turn reduce adverse events.

The VARK questionnaire is a validated tool used in assessing preferred learning styles developed by educator Neil Fleming in $1987 .{ }^{18}$ VARK represents four styles of learning: visual $(\mathrm{V})$, aural $(\mathrm{A})$, reading-writing $(\mathrm{R})$ and kinesthetic $(\mathrm{K})$. Learning styles can be categorised as: unimodal, bimodal or multimodal. VARK allows for individualisation of instruction and may ultimately improve the educational experience of learners. ${ }^{16}{ }^{18}{ }^{19}$ Current home dialysis training methods are not individualised according to learning style.

Over the last decade, expert opinions in home dialysis have encouraged programme to individualise training according to learning styles. ${ }^{20-22}$ However, there is limited literature examining the relationship between learning styles and patient outcomes. In this study, we examine the learning styles of prevalent home dialysis (home HD and PD) patients and their adverse event risk within 6 months of training completion stratified according to learning style. We hypothesised that differences in patients' learning styles are associated with differing risk of adverse events in both home HD and PD patients.

\section{METHODS \\ Study population and home dialysis training}

Recruitment took place between 1 March 2016 and 31 January 2019. Our study cohort consisted of prevalent adult patients ( $\geq 18$ years) who completed home dialysis training at the University Health Network, Toronto General Hospital (Toronto, Ontario, Canada). Patients were eligible for study inclusion if they were proficient in English, performing dialysis independently and were on home HD (4-6 treatments per week, 8 hours per session) or PD (continuous ambulatory PD or automated PD) for at least 6 months. Patients were not selected for this study based on literacy (although these data were collected). Instead all prevalent patients deemed suitable and safe to dialyse independently at home were deemed eligible for inclusion. We attempted to reduce any bias effect in our study by excluding patients receiving nursing assistance in the home for dialysis (figure 1). Patients who were blind or deaf were also excluded, as these impairments ruled out visual or auditory learning styles, respectively.

All patients were assessed by an interprofessional healthcare team to determine suitability for home dialysis. Patients pursuing home HD received training for a period of 8-12 weeks with 1:1 nursing care. They were provided with standardised training manuals, instructional videos along with hands-on teaching from the nurses. The training manuals and instructional videos covered basic dialysis concepts, focusing on troubleshooting problems related to vascular access and other complications. After training completion, home HD patients completed three written exams with a primary focus on issues related to access and complications. In order to successfully complete training, home HD patients required a score of at least $90 \%$. Of note, we accept patients with central venous catheters (CVCs) to our home HD programme. They are carefully trained to independently care for their catheter, occasionally with the use of a mirror. We endeavour to transition all patients to arteriovenous fistula or graft access in time and re-train them in cannulation when their new access is mature.

On the other hand, PD patients received training over a period of 1-2 weeks with 1:1 nursing care; receiving a standardised patient manual with hands-on teaching with the option of receiving additional instructional videos. Our PD patients did not have examinations at the end of training to certify competency.

\section{Data collection, measurements and definitions}

We received patient consent to review electronic medical records before questionnaire completion, and to collect demographic and clinical data (age, level of education, cause of end-stage renal disease, dialysis vintage, 
duration of training and complications on dialysis) for enrolled patients. At enrolment, patients were asked to complete the Rapid Estimate of Adult Literacy in Medicine (REALM) assessment to determine health literacy as well as the16-multiple choice VARK questionnaire (version 7.8). We used the VARK scoring system to determine learning styles based on questionnaire responses. If a patient exhibited a single learning style (unimodal) this was labelled accordingly (V, A, R or K). If a patient demonstrated preference for two learning styles (bimodal) or more than two learning styles (multimodal), the label reflected the combination of preferred styles (VA, VR, VK, AR, AK, RK, VAR, VAK, ARK, VRK, VARK). Any patient demonstrating a visual learning style ( $\mathrm{V}$ alone or in any combination) was considered a visual learner.

The primary outcome of the study was adverse events that were related to, or potentially related to, patient technique in performing dialysis or access self-care. We reviewed patient charts to identify adverse events for both home HD and PD patients occurring within 6 months of training completion. Adverse events during this time period may be more closely associated with training and learning styles than those events happening more remotely from the training period.

Home HD adverse events were defined as any arteriovenous fistula or graft needle dislodgement, access-related thrombosis, air embolism and catheter-related complications. Catheter related complications included catheter damage caused by patient, catheter-related bloodstream infections (CRBSIs), exit site infections and tunnel infections. CRBSIs were defined as a positive blood culture with clinical signs of an infection and no other source for infection apart from the catheter. CVC exit site infection was defined as the presence of tenderness and/or erythema occurring within $2 \mathrm{~cm}$ of the exit site along with purulent discharge. CVC tunnel site infection was defined as the same as an exit site infection but extending beyond $2 \mathrm{~cm}$ from the exit site. PD adverse events were PD peritonitis, wet contamination and PD catheter exit/tunnel site infections. PD catheter exit site infection was defined as the presence of either tenderness or erythema at the exit site along with purulent discharge. Wet contamination was defined as accidental disconnection during dialysis or if the twist clamp on the transfer set was left open. Prior adverse events while on other modalities of dialysis were not considered.

\section{Statistical analysis}

All continuous data variables are presented as means with $\mathrm{SD}$, whereas categorical data are presented as absolute values and percentages within groups. Statistical tests comparing categorical variables was done by $\chi^{2}$ test and the Kruskal-Wallis to compare continuous variables. We used logistic regression to compare learning styles and adverse events. Unadjusted and adjusted OR comparing rates of adverse events between learning style groups were performed. All statistical analyses were completed using SPSS statistical software V.25 (IBM).

\section{Patient and public involvement}

This study was designed without patient involvement. Patients were not invited to comment on the study design and were not consulted to develop patient relevant outcomes or interpret the results. Patients were not invited to contribute to the writing or editing of this document for readability or accuracy.

\section{RESULTS}

\section{Baseline characteristics}

One hundred and eighteen prevalent home dialysis patients were included in the study with 78 home HD patients and 40 PD patients. The average age was $52.02 \pm 13.51$ years with a fairly even distribution among gender, 60 males, 58 females for all home dialysis patients (table 1). PD patients were older with an average of $56.33 \pm 15.21$ years compared to home HD patients, $49.81 \pm 12.08$ years (table 1 ). The average vintage for all home dialysis patients was $4.03 \pm 7.25$ years; however, subgroup analysis revealed that home HD patients had longer vintage $(4.90 \pm 7.48$ years $)$ than PD patients $(2.33 \pm 6.54$ years $)$. As training approaches remained similar over these time periods, we did not expect a significant era effect. Thirty-one $(77.5 \%)$ PD patients had no prior renal replacement therapy (RRT).

Diabetes, hypertension, IgA nephropathy and FSGS were the leading causes of end-stage renal disease in our study population, accounting for nearly $50 \%$ of all cases. In terms of education, only three patients did not achieve a level of high school level education or higher. Five patients had poor health literacy based on REALM scores (table 1).

We observed variations in composite learning styles among all patients. Both unimodal and bimodal styles had 17 patients each, whereas a total of 84 patients had multimodal learning styles. The majority of patients displayed multimodal learning preferences with a combination of at least three composite learning styles, VAR, VAK, VRK, ARK or VARK (figure 2). No patients were found to be unimodal A; meaning that no patient had an auditory learning style not associated with other learning styles. Visual learning style was the most predominant with more than $60 \%$ of patients having a visual component within their composite learning style. There were no significant differences nor trend in adverse event rates observed within the auditory, reading-writing and kinesthetic learning style domains for all patients.

\section{Adverse events}

Thirty patients had a total of 53 adverse events during the study. Non-visual learners had an event rate of 33 per 100 patient-years, whereas, visual learners had 19 events per 100 patient-years. Among all home dialysis patients, nonvisual learners were 4.35 times more likely to have a single adverse event within 6 months of completing their training compared with visual learners $(\mathrm{p}=0.001)$ (table 2). After adjusting for age, gender, dialysis modality, training 
Table 1 Home dialysis patient demographics

\begin{tabular}{|c|c|c|c|}
\hline & $\begin{array}{l}\text { Home dialysis patients } \\
\mathrm{n}=118\end{array}$ & $\begin{array}{l}\text { Home HD patients } \\
n=78\end{array}$ & $\begin{array}{l}\text { PD patients } \\
\mathrm{n}=40\end{array}$ \\
\hline Age, years, mean $\pm S D$ & $52.02 \pm 13.51$ & $49.81 \pm 12.08$ & $56.33 \pm 15.21$ \\
\hline $\begin{array}{l}\text { Gender } \\
\text { Female, n (\%) }\end{array}$ & $58(49.2)$ & $38(48.7)$ & $20(50)$ \\
\hline $\begin{array}{l}\text { Dialysis vintage } \\
\text { Years, mean } \pm S D\end{array}$ & $4.03 \pm 7.25$ & $4.90 \pm 7.48$ & $2.33 \pm 6.54$ \\
\hline $\begin{array}{l}\text { Duration of training } \\
\text { Weeks, mean } \pm S D\end{array}$ & $6.35 \pm 5.35$ & $8.71 \pm 5.15$ & $1.75 \pm 0.80$ \\
\hline \multicolumn{4}{|l|}{ Cause of End-stage renal disease, $n(\%)$} \\
\hline Cardiorenal syndrome & $2(1.7)$ & $1(1.3)$ & $1(2.5)$ \\
\hline Calcineurin Inhibitor, toxicity & $2(1.7)$ & $1(1.3)$ & $1(2.5)$ \\
\hline Cystinuria & $2(1.7)$ & $1(1.3)$ & $1(2.5)$ \\
\hline Diabetes & $16(13.6)$ & $9(11.5)$ & $7(17.5)$ \\
\hline Focal Segmental Glomerulosclerosis & $12(10.2)$ & $8(10.3)$ & $4(10)$ \\
\hline Henoch-Schonlein purpura & $2(1.7)$ & $2(2.6)$ & - \\
\hline Hypertension & $12(10.2)$ & $5(6.4)$ & $7(17.5)$ \\
\hline Hypoplastic kidneys & $2(1.7)$ & $2(2.6)$ & - \\
\hline IgA nephropathy & $13(11)$ & $9(11.5)$ & $4(10)$ \\
\hline Lupus nephritis & $8(6.8)$ & $5(6.4)$ & $3(7.5)$ \\
\hline Membranoproliferative glomerulonephritis & $6(5.1)$ & $5(6.4)$ & $1(2.5)$ \\
\hline Polycystic kidney disease & $7(5.9)$ & $6(7.7)$ & $1(2.5)$ \\
\hline Reflux nephropathy & $5(4.2)$ & $5(6.4)$ & - \\
\hline Renal vasculitis & $6(5.1)$ & $5(6.4)$ & $1(2.5)$ \\
\hline Thrombotic microangiopathy & $2(1.7)$ & $1(1.3)$ & $1(2.5)$ \\
\hline Unknown & $8(6.8)$ & $6(7.7)$ & $2(5.0)$ \\
\hline Other* & $13(11)$ & $7(8.9)$ & $6(15)$ \\
\hline \multicolumn{4}{|l|}{ Prior RRT, n (\%) } \\
\hline None & $42(35.6)$ & $11(14.1)$ & $31(77.5)$ \\
\hline In-centre intermittent HD & $50(42.4)$ & $42(53.8)$ & $8(20)$ \\
\hline PD & $9(7.6)$ & $9(11.5)$ & - \\
\hline Renal transplant & $17(14.4)$ & $16(20.5)$ & $1(2.5)$ \\
\hline \multicolumn{4}{|l|}{ Highest level of education, $\mathrm{n}(\%)$} \\
\hline Elementary school & $3(2.5)$ & $2(2.6)$ & $1(2.5)$ \\
\hline High school & 20 (16.9) & $11(14.1)$ & $9(22.5)$ \\
\hline College & 40 (33.9) & $21(26.9)$ & $19(47.5)$ \\
\hline University & $55(46.6)$ & $44(56.4)$ & $11(27.5)$ \\
\hline \multicolumn{4}{|l|}{ REALM health literacy, $n$ (\%) } \\
\hline Poor & $5(4.2)$ & $5(6.4)$ & - \\
\hline Good & $113(95.8)$ & $73(93.6)$ & $40(100)$ \\
\hline \multicolumn{4}{|l|}{ Learning modality, n (\%) } \\
\hline Unimodal & $17(14.4)$ & $14(17.9)$ & $3(7.5)$ \\
\hline Bimodal & $17(14.4)$ & $13(16.7)$ & $4(10)$ \\
\hline Multimodal & $84(71.2)$ & $51(65.4)$ & 33 (82.5) \\
\hline
\end{tabular}

HD, haemodialysis; PD, peritoneal dialysis; REALM, Rapid Estimate of Adult Literacy in Medicine; RRT, renal replacement therapy. 


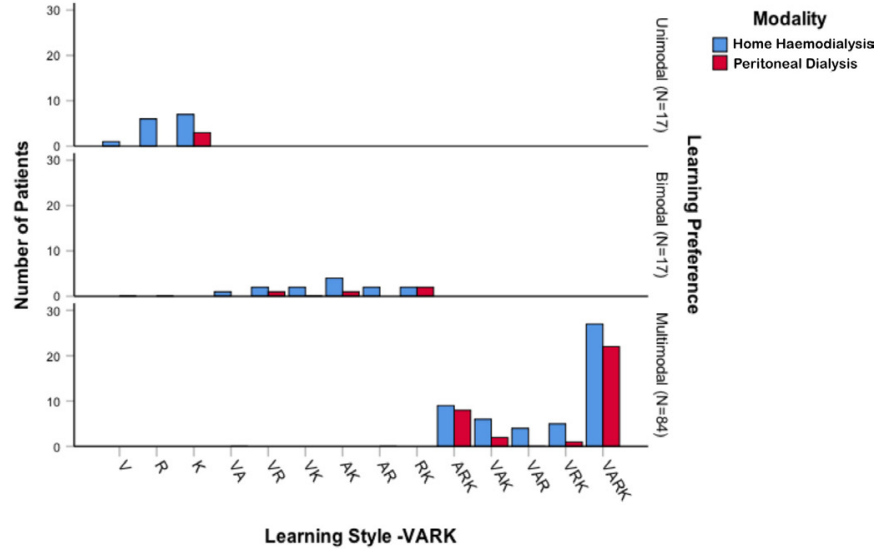

Figure 2 Learning style differences among peritoneal dialysis and home haemodialysis patients. VARK, Visual, Aural, Reading-writing and Kinesthetic.

duration, dialysis vintage, prior RRT, visual impairment, level of education and REALM literacy, an adverse event was four times more likely to occur among non-visual learners compared with visual learners $(\mathrm{p}=0.008)$. In the subgroup analysis, home HD patients had a statistically significant higher likelihood of an adverse event among non-visual learners before (OR: 9.63; $\mathrm{p}=0.001)$ and after adjustment (OR 11.1; $\mathrm{p}=0.003$ ). On the other hand, a subgroup analysis of PD patients revealed a trend for more adverse events in visual compared with non-visual learners (OR: 1.60; $\mathrm{p}=0.694$ ) (table 2). There were no deaths during the study period.

The most common adverse event among home HD patients were CVC exit site infections. There were 17 exit site infections occurring at a rate of 133 events per 100 patient-years (table 3 ). More than $50 \%$ of all exit site infections were attributed to coagulase negative staphylococcal and Staphylococcus aureus organisms. S. aureus was the most common cause of CVC related bacteraemia in patients.

Wet contaminations were the most common event among PD patients with 11 reported episodes, occurring at 56 events per 100 patient-years. Two episodes of PD peritonitis were documented for an event rate of 10 per 100 patient-years (table 3 ). The organisms causing peritonitis were Enterobacter cloacae and Enterococcus durans.

\section{DISCUSSION}

To our knowledge, this is the first study to evaluate the association between patient outcomes and learning styles in both PD and home HD patients. Our findings demonstrate that differences in learning styles for both home HD and PD patients exist. Furthermore, home dialysis patients with visual learning styles may be at risk for fewer adverse events within the first 6 months of training completion. Adverse events may be more prevalent if instructional methods of home dialysis training and patient learning styles are discordant. Therefore, individualisation of training according to learning styles is essential to limit risk among incident home dialysis patients.

In individualising teaching methods, administrators and healthcare professionals must become familiar with strengths and weakness of various learning styles. Attempts to individualise training methods without truly understanding the differences in learning styles may complicate training process for both patients and healthcare practitioners, potentially leading to greater harm. For example, visual learners have strong preferences for algorithms, diagrams, charts, graphs and flow charts. Auditory learners usually excel in situations where information is heard or spoken. ${ }^{18} 19$ These learners thrive in group discussions, lectures, verbal troubleshooting and have a tendency for talking out aloud and to themselves. Reading-writing learners have a penchant for using manuals, reports and use internet search engines for knowledge acquisition. Lastly, kinesthetic learners rely on demonstrations, past experiences, simulations and videos. ${ }^{18} 19$ Our current instructional methods for both home HD and PD favour visual, reading and kinesthetic learners through the provision of video clips, reading material and hands-on teaching.

Our study showed that home HD patients who were non-visual learners had a significant increased likelihood of having a single adverse event compared to visual learners. This confirms findings in previously published data demonstrating an increased risk of adverse events among non-visual learners on home HD. ${ }^{23}$ We observed a trend towards more adverse events, specifically, wet contamination episodes among PD patients but this lacked statistical significance. Additionally, episodes of wet contaminations and peritonitis are infrequent relative to CVC related complications such as exit site infections and bacteraemia. Most importantly, this highlights differences in training between the two modalities; simply put, home HD is more complex and carries a greater risk of having an adverse event. This adverse event risk is further amplified among non-visual learners, as we did not find any significant risk attributable to auditory, reading-writing nor kinesthetic learning styles for both PD and home HD patients.

Currently, there is limited evidence on the ideal content structure and duration of training for home dialysis patients. In our study, all patients completed training successfully implying that learning styles may not have an impact on knowledge acquisition. Rather, the longterm retention of knowledge and subsequent recall of information may be affected if learning styles have not been accounted for, possibly explaining why some of our patients with non-visual learning styles were initially successful with their training yet had an increased risk for adverse events within 6 months of training completion.

The event rate reported in our study for home HD patients is higher than that published in previous studies. ${ }^{12}{ }^{24}$ Published data on home HD patient adverse events have focused on mainly serious adverse events; primarily hospitalisations and other life-threatening 

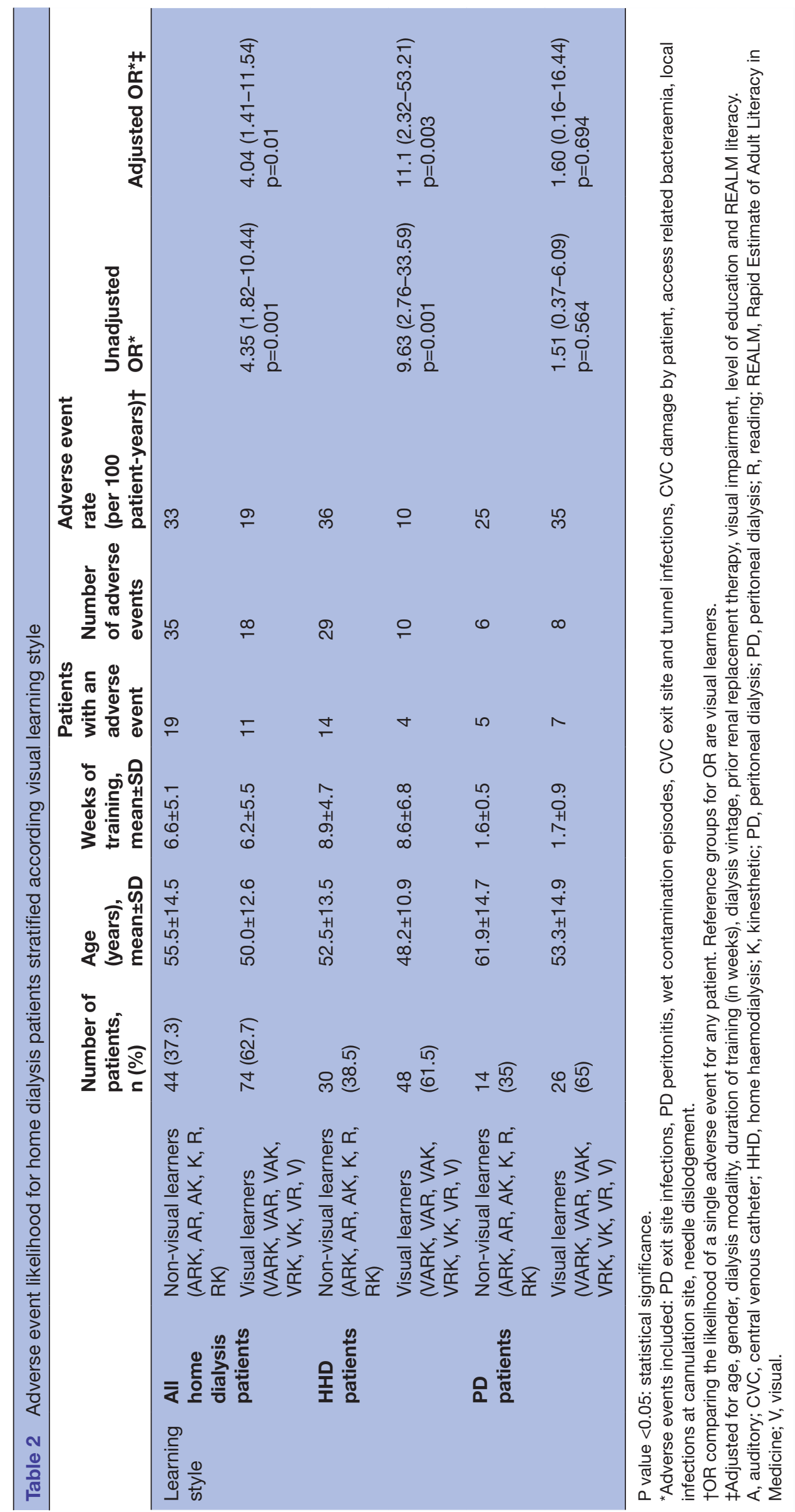
Table 3 Types of adverse events for home dialysis patients

Home dialysis adverse events within 6 months of training completion

\begin{tabular}{lcc}
\hline & $\begin{array}{l}\text { Number of } \\
\text { events }\end{array}$ & $\begin{array}{l}\text { Event rate } \\
\text { (per 100 patient- } \\
\text { years) }\end{array}$ \\
\hline HHD adverse events & 2 & 10 \\
\hline Button hole site infection & 2 & 86 \\
\hline CVC-related bacteraemia & 11 & 8 \\
\hline CVC damaged & 1 & 133 \\
\hline CVC exit site & 17 & 31 \\
\hline CVC tunnel line infection & 4 & 34 \\
\hline Graft Infection & 2 & 7 \\
\hline Needle dislodgement & 2 & 10 \\
\hline PD adverse events & & 5 \\
\hline Peritonitis & 2 & 56 \\
\hline Exit site infections & 1 & 11 \\
\hline Wet contamination & 11 & \\
\hline
\end{tabular}

${ }^{\star}$ Event rate for HHD and PD patients at risk; all 40 PD patients were at risk for PD adverse events; $40 \mathrm{HHD}$ patients were at risk for button hole site infections; $26 \mathrm{HHD}$ patients were at risk for CVC related bacteraemia, damage to CVC, CVC exit site and tunnelled infection; $12 \mathrm{HHD}$ patients were at risk for graft infections and 52 were at risk for needle dislodgement during dialysis therapy.

CVC, central venous catheter; HHD, home haemodialysis; PD, peritoneal dialysis.

events. $^{12}$ However, CRBSIs may develop from unrecognised exit-site and tunnel infections. Furthermore, CRBSIs are associated with increased morbidity, hospitalisation and death. ${ }^{25-27}$ Therefore, in our study, we classified all exit site infections and tunnel line infections as adverse events given that they are commonly attributed to poor dressing care along with a breakdown in aseptic technique. $^{27-29}$ Capturing exit-site and tunnel infections likely accounts for the higher adverse event rate that we noted in our study for HHD patients compared to what has been previously reported. The stepwise and algorithmic process described in our current home HD instructional manual in caring for exit sites may also favour visual learning, possibly explaining the higher rates observed among non-visual learners.

Peritonitis is a major complication in PD patients and is associated with an increased risk of technique failure and in some cases death. ${ }^{30-32}$ The 2016 ISPD (International Society for Peritoneal Dialysis) peritonitis recommendations stated that centres should aim to have a rate of $\leq 0.5$ episodes/patient-year. ${ }^{33}$ Additionally, the risk of peritonitis is increased when wet contamination episodes occur without antibiotic prophylaxis. ${ }^{13}$ Although we routinely give antibiotic prophylaxis for wet contamination events, we classified them as adverse events to identify patients at risk given that our local peritonitis rates are exceedingly low $(<0.2$ episodes/patient-year). The low rates of both wet contamination and peritonitis events may also be attributable to intrinsic simplicity in performing PD; basically, fewer steps compared to home HD to commit errors in aseptic technique and practices.

Rates of adverse events relative to learning style may differ across various home HD and PD programmes depending on the instructional method that is used. For instance, a programme that has more effective instructional tools in catering for non-visual learners may see less rates of adverse events compared to our findings. The development of diverse instructional methods catering for all learning style may improve knowledge retention and reduce adverse event risk. Furthermore, a multisensory approach to the educational process for home dialysis patients may be a viable alternative where individualisation of instruction is not feasible. ${ }^{34}$

Although our study is novel in examining learning styles of both home HD and PD patients, there were some important limitations that must be highlighted. First, this was a small single-centre observational study which was not powered to detect other important measurements such as mortality risk between different learning styles. Additionally, the small number of PD patients and PD-specific adverse events relative to home HD within our study may have also been underpowered to detect differences in adverse event rate. The true incidence of wet contamination rates may have also been underestimated as it is dependent on patient notification. For example, patients may have taken wet contamination antibiotic prophylaxis after an event without informing our PD programme, reducing documented event rate. Additionally, although VARK has been validated in general populations it has not yet been validated in home HD and PD patients. ${ }^{35}$ Lastly, VARK looks at one aspect of learning and does not factor in personality, motivation, native environments nor introversion-extraversion traits. ${ }^{19}$ These other factors also play important roles in knowledge acquisition and retention.

\section{CONCLUSIONS}

In using VARK as a tool, our study has demonstrated that learning style differences exist in both PD and home HD patients. As home dialysis continues to grow, patients are given more responsibility in performing dialysis in the home. Therefore, it is important in ensuring that knowledge is delivered in a manner that is congruent with learning styles of patients. Future quality assurance initiatives aimed at improving training processes for home dialysis patients could use VARK questionnaires or similar tools to identify patient learning styles at the beginning of training. Training can be individualised according to the patient's learning style and may also highlight areas of deficiency in instructional methods, paving the way for innovative curriculum changes in home dialysis training.

Twitter Bourne Lewis Auguste @bourneauguste 
Contributors Study concept and design: BLA, MMC, JMB, CC. Acquisition, analysis or interpretation of data: BLA, MG, CK, TS, MMC. Drafting of the manuscript: BLA, MG, CK, TS. Critical revision of the manuscript for important intellectual content: BLA, MG, CK, TS, MMC, JMB, CC. Study supervision: CC. All authors approved the final version of the submitted manuscript.

Funding The authors have not declared a specific grant for this research from any funding agency in the public, commercial or not-for-profit sectors.

Competing interests None declared.

Patient consent for publication Not required.

Ethics approval We received research ethics approval for this study from the University Health Network Research Ethics Board (16-5144.4-AE).

Provenance and peer review Not commissioned; externally peer reviewed.

Data availability statement All data relevant to the study are included in the article or uploaded as supplementary information. No additional data available.

Open access This is an open access article distributed in accordance with the Creative Commons Attribution Non Commercial (CC BY-NC 4.0) license, which permits others to distribute, remix, adapt, build upon this work non-commercially, and license their derivative works on different terms, provided the original work is properly cited, appropriate credit is given, any changes made indicated, and the use is non-commercial. See: http://creativecommons.org/licenses/by-nc/4.0/.

ORCID iD

Bourne Lewis Auguste http://orcid.org/0000-0002-6741-2427

\section{REFERENCES}

1 Jain AK, Blake P, Cordy $\mathrm{P}$, et al. Global trends in rates of peritoneal dialysis. JASN 2012;23:533-44.

2 Klarenbach S, Manns B. Economic evaluation of dialysis therapies. Semin Nephrol 2009;29:524-32.

3 Klarenbach SW, Tonelli M, Chui B, et al. Economic evaluation of dialysis therapies. Nat Rev Nephrol 2014;10:644-52.

4 Kooistra M, Vos J, Koomans H, et al. Daily home haemodialysis in the Netherlands; effects on metabolic control, heamodynamics, and quality of life. Nephrology Dialysis Transplantation 1998;13:2853-60.

5 Rivara MB, Mehrotra R. The changing landscape of home dialysis in the United States. Curr Opin Nephrol Hypertens 2014;23:586-91.

6 Jones JP, Leonard EF, Sandhu G, et al. Daily ultrafiltration results in improved blood pressure control and more efficient removal of small molecules during hemodialysis. Blood Purif 2013;34:325-31.

7 Nesrallah GE, Lindsay RM, Cuerden MS, et al. Intensive hemodialysis associates with improved survival compared with conventional hemodialysis. JASN 2012;23:696-705.

8 Walsh M, Culleton B, Tonelli M, et al. A systematic review of the effect of nocturnal hemodialysis on blood pressure, left ventricular hypertrophy, anemia, mineral metabolism, and health-related quality of life. Kidney Int 2005;67:1500-8.

9 Auguste BL, Bargman JM. Incremental peritoneal dialysis: new ideas about an old approach. Semin Dial 2018;31:445-8.

10 François K, Bargman JM. Evaluating the benefits of home-based peritoneal dialysis. Int J Nephrol Renovasc Dis 2014;7:447-55.

11 Menon MK, Naimark DM, Bargman JM, et al. Long-term blood pressure control in a cohort of peritoneal dialysis patients and its association with residual renal function. Nephrol Dial Transplant 2001;16:2207-13.

12 Tennankore KK, d'Gama C, Faratro R, et al. Adverse technical events in home hemodialysis. Am J Kidney Dis 2015;65:116-21.
13 Yap DYH, Chu WL, Ng F, et al. Risk Factors and Outcome of Contamination in Patients on Peritoneal Dialysis--A Single-Center Experience of 15 Years. Perit Dial Int 2012;32:612-6.

14 Morony S, Flynn M, McCaffery KJ, et al. Readability of written materials for CKD patients: a systematic review. Am J Kidney Dis 2015;65:842-50.

15 Thepsatitporn S, Pichitpornchai C. Visual event-related potential studies supporting the validity of VARK learning styles' visual and read/write learners. Adv Physiol Educ 2016;40:206-12.

16 Peyman H, Sadeghifar J, Khajavikhan J, et al. Using VARK approach for assessing preferred learning styles of first year medical sciences students: a survey from Iran. J Clin Diagn Res 2014;8:GC01-4.

17 James S, D'Amore A, Thomas T. Learning preferences of first year nursing and midwifery students: utilising VARK. Nurse Educ Today 2011;31:417-23.

18 Fleming N, Baume D. Learning styles again: VARKing up the right tree! Educ Dev 2006;7.

19 Inott T, Kennedy BB. Assessing learning styles: practical tips for patient education. Nurs Clin North Am 2011;46:313-20.

20 Figueiredo AE, Bernardini J, Bowes E, et al. A Syllabus for teaching peritoneal dialysis to patients and caregivers. Perit Dial Int 2016;36:592-605.

21 Marshall M, Chan CT. Implementing hemodialysis in the home: a practical manual. Indianapolis, Indiana, International Society of hemodialysis, 2015.

22 Wingard R. Patient education and the nursing process: meeting the patient's needs. Nephrol Nurs J 2005;32:211-4. quiz 215.

23 Auguste BL, Al-Muhaiteeb A, Chan CT. The effect of learning styles on adverse events in home hemodialysis patients. CJASN 2018;13:782-3.

24 Wong B, Zimmerman D, Reintjes F, et al. Procedure-related serious adverse events among home hemodialysis patients: a quality assurance perspective. Am J Kidney Dis 2014;63:251-8.

25 Dhingra RK, Young EW, Hulbert-Shearon TE, et al. Type of vascular access and mortality in U.S. hemodialysis patients. Kidney Int 2001;60:1443-51.

26 Lee T, Barker J, Allon M. Tunneled catheters in hemodialysis patients: reasons and subsequent outcomes. American Journal of Kidney Diseases 2005;46:501-8.

27 Miller LM, Clark E, Dipchand C, et al. Canadian Society of nephrology vascular access work G: hemodialysis tunneled catheter-related infections. Can J Kidney Health Dis 2016;3:2054358116669129.

28 Amini M. Evaluation the effectiveness of an educational intervention to decrease central line-associated bloodstream infections among hemodialysis patients. Am J Infect Control 2016;44:1703-4.

29 Mermel LA. Prevention of intravascular Catheter-Related infections. Ann Intern Med 2000;132:391-402.

30 Davenport A. Peritonitis remains the major clinical complication of peritoneal dialysis: the London, UK, peritonitis audit 2002-2003. Perit Dial Int 2009;29:297-302.

31 Moloi MW, Kajawo S, Noubiap JJ, et al. Prevalence of peritonitis and mortality in patients treated with continuous ambulatory peritoneal dialysis (CapD) in Africa: a protocol for a systematic review and meta-analysis. BMJ Open 2018;8:e020464.

32 Pérez Fontan M, Rodríguez-Carmona A, García-Naveiro R, et al. Peritonitis-related mortality in patients undergoing chronic peritoneal dialysis. Perit Dial Int 2005;25:274-84.

33 Li PK-T, Szeto CC, Piraino B, et al. Ispd peritonitis recommendations: 2016 update on prevention and treatment. Perit Dial

34 Neville A, Jenkins J, Williams JD, et al. Peritoneal dialysis training: a multisensory approach. Perit Dial Int 2005;25:S149-51.

35 Leite WL, Svinicki M, Shi Y. Attempted validation of the scores of the VARK: learning styles inventory with Multitrait-Multimethod confirmatory factor analysis models. Educ Psychol Meas 2010;70:323-39. 